\title{
QUEEN'S
UNIVERSITY
BELFAST
}

\section{The Participation of Parents of Disabled Children and Young People in Health and Social Care Decisions}

McNeilly, P., Macdonald, G., \& Kelly, B. (2017). The Participation of Parents of Disabled Children and Young People in Health and Social Care Decisions. Child: Care, Health and Development, 43(6), 839-846. https://doi.org/10.1111/cch.12487

\section{Published in:}

Child: Care, Health and Development

\section{Document Version:}

Peer reviewed version

\section{Queen's University Belfast - Research Portal:}

Link to publication record in Queen's University Belfast Research Portal

\section{Publisher rights}

(c) 2017 John Wiley \& Son.

This work is made available online in accordance with the publisher's policies. Please refer to any applicable terms of use of the publisher. Postprint: 2 year embargo.

\section{General rights}

Copyright for the publications made accessible via the Queen's University Belfast Research Portal is retained by the author(s) and / or other copyright owners and it is a condition of accessing these publications that users recognise and abide by the legal requirements associated with these rights.

Take down policy

The Research Portal is Queen's institutional repository that provides access to Queen's research output. Every effort has been made to ensure that content in the Research Portal does not infringe any person's rights, or applicable UK laws. If you discover content in the Research Portal that you believe breaches copyright or violates any law, please contact openaccess@qub.ac.uk. 


\title{
The participation of parents of disabled children and young people in health and social care decisions.
}

\begin{abstract}
Background: There is widespread acceptance that parents should be fully involved in decisions about their son or daughter's health and social care. This is reflected in partnership models of practice as well as local and national policy across the UK. Previous research indicates that parents' experiences of decision making with professionals are mixed.
\end{abstract}

Aim: The research reported here aimed to explore parents' experiences of participating in decisions made with professionals about their disabled son or daughter's care.

Design: Mixed methods including survey methodology and qualitative in depth interviews.

Setting and participants: The research was conducted in one Trust in Northern Ireland. Participants were 77 parents of children and young people with a range of impairments aged between 3 and 28 years.

Results: Three themes emerged from the data: taking the lead, not knowing and getting the balance right. Parents wanted to be involved in all aspects of decision making. While parents reported many examples of good practice there were also times when they did not feel listened to or did not have enough information to inform decisions.

Discussion and conclusion: Parents in this research recounted positive as well as negative experiences. Parents took on a protective role when decisions were made about their son or daughter and at times reported the need to 'fight' for their child. The provision of information remains problematic for these families and at times this created a barrier to parents' participation in decision making. Partnership approaches to care that recognise parents' expertise are particularly important to parents when decisions are made with professionals. 


\section{The participation of parents of disabled children and young people in health and social care decisions.}

\section{Introduction}

The participation of service users in decisions that affect them is a public policy priority (Franklin and Sloper, 2009) and an essential aspect of best practice in health and social care. It is hoped that, by empowering and involving service users, we will more accurately be able to meet their individual needs, recognise them as experts in their own lives and target resources where they are most needed.

Where disabled children and young people are concerned, parents (or those having parental responsibility) occupy a key role in ensuring that disabled children and young people receive the health and social care that they need. Parents have previously report the emotional demands of being responsible for their child's care when a child has a long-term condition (Smith, 2013) or disability (Maddison and Beresford, 2012a); however, they develop much expertise in meeting their child's needs.

Previous studies demonstrate that parents want to be involved in decision making with professionals about their disabled child's care and want to take an increasing role in decision making as they develop confidence in their caring role (Egilson, 2011). However, within the literature, parents' experiences of involvement in decision making are mixed. Parents in some studies have reported very positive experiences and expressed much satisfaction with their involvement (Wood et al. 2009; Hyde et al. 2010; Pilnick et al. 2011). In other studies, parents have identified that they did not always feel listened to by professionals and their expertise was not always taken into consideration when decisions were made (Lundeby and 
Tossebro, 2008; Wodehouse and McGill, 2009; Care Quality Commission, 2012; Hayles et al. 2015).

Here we report findings of mixed methods ESRC funded $\mathrm{PhD}$ research 'The participation of disabled children, young people and their parents in health and social care decisions'. The research aimed to explore the meaning, experience and outcomes of participation by these stakeholders. Children and young people's experiences and issues around three way participation between parents, children and professionals are reported elsewhere (see McNeilly et al. 2015). In this article we report parents' experiences of participating in decisions about their son or daughter's health and/or social care and discuss implications for policy, practice and services. The terms participation and involvement are used synonymously here. Regardless of age, parents in this research referred to their 'child' and this is retained in their accounts here.

\section{Method}

Both quantitative and qualitative methods were employed in the research (1) surveys and (2) in depth, semi-structured interviews with parents. The survey method was used to collect data from parents about their experiences but also to inform the more in depth, qualitative aspect of the research. Questionnaires were piloted with four parents of disabled children and minor amendments made as recommended. The semi-structured interview questions were based on themes emerging from the research literature and in consultation with two parents from a parent-led advocacy group. The qualitative aspect of the research was grounded in a phenomenological perspective which previous authors have argued is particularly appropriate for researching the needs and wishes of those who use services (Duffy, 2008), 
Purposive sampling is most frequently used in phenomenological studies as a mechanism for including participants with experience of the phenomenon of interest in research(Streubert and Carpenter, 2011) and was therefore employed here. Parents were recruited via a local parent advocacy group. Participants who completed the postal survey (response rate 24\%) were 77 parents ( 70 mothers and 7 fathers) of children and young people with a range of physical (39\%), cognitive (75\%), sensory (27\%) and communication (25\%) impairments aged between 3 and 28 years from one Health and Social Care Trust in Northern Ireland. Subsequently, in depth, semi-structured interviews were conducted with 26 mothers and 4 fathers, whose children were between the ages of 3 and 24 years. Parents were interviewed in their own home at a time that suited them.

Ethical approval was granted by the University and Trust ethics committees in addition to the Office of Research Ethics Committees Northern Ireland. Information packs, containing a covering letter, information about the research, a copy of the survey and a reply slip were distributed via the local collaborators. Replies and completed surveys were posted back directly to the researcher. The researcher telephoned parents who expressed an interest in participating in an interview. Parents were provided with further information before the interview commenced and given the opportunity to opt out at this stage, although none did. Written consent was obtained. The boundaries of confidentiality were explained to parents, and with prior written consent, interviews were recorded and transcribed using anonymous labels rather than personal identifiers. Data was stored securely in accordance with university policy based on the Data Protection Act (1998).

Survey data was analysed using SPSS v 18. Interview data was analysed using NVivo 8 computer software and informed by Dahlberg et al.'s (2008) five guiding principles for the 
analysis of phenomenological data. It is important to emphasise that these were not used as a series of rigid steps but used as a set of principles to guide the analysis process:

1. Read the whole text, moving from the whole to the parts and vice versa.

2. Create a series of themes and subthemes to establish a preliminary understanding.

3. Search for meanings in order to further develop this understanding.

4. Make tentative interpretations using all relevant data.

5. Compare tentative interpretations for similarity and difference working towards a new whole.

\section{Results}

The survey and interview data both indicated that parents made a wide variety of decisions about their son or daughter's health and social care - decisions about physical care, psychological care, discharge from hospital, transition to adult services, family support needs and direct payments. Parents felt strongly that they should be involved in all decisions relating to their child's care. Of those surveyed, $91 \%$ of parents indicated that it was 'extremely important' that they participated in healthcare decisions about their child and 90\% said the same of social care decisions.

The pattern of responses to the parent survey ( $90 \%$ from mothers and $10 \%$ from fathers), the uptake of parent interviews ( $87 \%$ mothers and $13 \%$ fathers), and data obtained during the course of the parent interviews, all strongly suggest that it was mothers who took the lead role in care giving and decision making. However, according to the mothers, fathers played a vital supportive role. Mothers described them as 'anchors', 'a tower of strength', someone who could be relied upon to listen to them, share responsibility and play a positive role in the life of their child. Three themes emerged from the data: taking the lead, not knowing and getting the balance right: parent or professional as expert. 


\section{Taking the lead}

It was evident from parents' accounts that they felt the need to take the lead when decisions were made about their son or daughter. Two subthemes emerged from the parent interviews in relation to 'taking the lead': 'fighting for the child' and 'protecting yet preparing'.

\section{Fighting for the child}

The need to fight for their child was threaded throughout many parents' accounts of participation in decision making. At times, parents reported feeling frustrated at the length of time it took to access required resources and, for many, there was a sense that they had to fight for whatever they got. Despite this finding, most parents who took part in the research reported very positive relationships with professionals and recounted stories of professionals going 'over and above' their call of duty. Positive relationships facilitated and fostered parents' participation in decisions about their child. Parents held in high regard those professionals who were perceived to: care about them, listen to them, follow through on promises and who were trustworthy and knowledgeable. However, there were times when parents found it difficult to challenge professionals. In one case, professionals repeatedly tried (unsuccessfully) to retrieve a blood sample from a young person, despite his mother saying from the outset he would need sedation:

They would say 'We don't give sedation for something as minor a blood test...' They had tunnel vision, it was their way or no way.

[Mother of a 16 year old young person with cognitive, sensory, communication impairments and autism] 
Parents often felt vulnerable when they challenged professional decisions and were concerned about jeopardising the relationship they had with them. In some cases parents sought private care when they felt unable to challenge professional opinion as in the following example:

The consultant said it was possible that he was traumatised and if he wasn't speaking at 5 to bring him back and re-evaluate him... I knew he had it [autism] and I wanted early intervention. I didn't want to lose 3 years so I took him privately. He had hand flapping, he had all the classic symptoms, he'd no speech, no eye contact and was extremely placid, I knew.

[Mother of a 7 year old child with autism]

\section{Protecting yet preparing}

In the interviews, parents also expressed the need to protect their child from finding out about their impairment or diagnosis. This was a source of much anxiety for many parents who were at times unsure of what information to give children and young people and at what stage. Parents spoke of wanting to keep their son or daughter 'in a cocoon' and treading a fine line between protecting them and encouraging independence. Parents had concerns that if they shared full information about their diagnosis their son/daughter would feel different or lose their confidence. This was particularly difficult as, in many cases, children did not view themselves as disabled:

...he said 'but I'm a normal boy mummy' and I want to keep things as normal as possible but I don't know how long I'll be able to do that...

[Mother of 2 disabled children]

With only one exception, parents felt that they were best placed to give their child information (or indeed to withhold it), although many struggled with how best to do this and 
some waited until their son/daughter asked them directly . One parent's daughter, who had not been told about her diagnosis, took her family by surprise when she announced at a family gathering 'I'm just a Down's syndrome kid'.

Parents were also often reluctant to plan for the future. Indeed, thoughts of the future caused much anxiety as one mother explained:

I try not to think about it because... you'd drive yourself insane if you look too far ahead, so I sort of try and take one year at a time...

[Mother of a 7 year old with physical, cognitive, communication impairments and autism]

Despite the finding that parents unequivocally worried about the future (when they could no longer look after their child), only a minority spoke about actively fostering their child's participation in decisions that affected them as a mechanism for developing their confidence and future independence. For most, meeting their child's needs was all consuming and a major part of their role as a parent was to advocate and make decisions for their child.

\section{Not knowing}

In the survey, parents were asked about information relating to their child at the time of diagnosis and since the time of diagnosis. More than half of parents surveyed (53\%) said that they had not received enough information at the time of diagnosis and $27 \%$ said that they had not received enough information following the diagnosis. Parents were also asked in the survey about information regarding available health and social care services and how to access these. Again, over a third of parents surveyed had not received enough information about health or social services or how to access them. 
In the survey, parents were asked where they obtained information to help them make decisions about their son/daughter's care. The most common source of information was other parents and professionals (see Table 1). Around a third of parents obtained information from relevant voluntary organisations and one third of parents used the internet to assist them in making healthcare decisions. The internet was used less commonly to inform social care decisions. In the parent interviews, there was an overall sense that parents had to find information out for themselves about their child's impairment and what services were available, even when they received regular support from professionals.

Two sub themes emerged from the parent interviews around knowing and not knowing: searching for a diagnosis and searching and researching over the years.

\section{Searching for a diagnosis}

Prior to diagnosis many parents were concerned and anxious about their child. Despite reassurances from professionals that nothing was wrong or that they should 'wait and see', parents were pro-active in seeking information for themselves at this time. One parent said that searching for information in the early stage was underpinned by the emotional trauma of finding out that her son had an impairment:

Well, when [son] was born, they wouldn't tell me at the start. I knew the minute they handed him to me he was Down's syndrome... and I couldn't accept it...I just couldn't.

[Mother of a 19 year old young person with physical, cognitive, sensory and communication impairment] 
In another family, a parent who already had one disabled child with very complex needs did not want information about her second son's impairment despite her own concerns about his development:

....at two and a half, there were concerns and ... I could not do it...and...the doctor said to me 'I have a fair idea about him' and I went 'Don't tell me'. I couldn't hear it. I knew he was going to say autistic spectrum and I could not hear it....Talk about going into denial, I couldn't get my head buried far enough... .

[Mother of two disabled children]

\section{Searching and researching over the years}

The provision of timely, accurate and appropriate information could facilitate or hinder the participation of parents. There was evidence that limited access to information at times led to difficulties in terms of understanding professionals' roles and wider health and social care service structures or more broadly, what services were available and this served as a barrier to participation.

Parents obtained much information from other parents or parent groups, a finding reflected in both the survey and parent interviews. Parents reported belonging to many parent groups, either within or outside school where they availed of information and support. However, parents sometimes missed out on important information, for example, support options, school options or benefits that may have eased financial difficulties. Parents sometimes found out information by chance, for example, from a bus driver, a therapist who was treating the 
parent or a professional who was not involved in their care but who had knowledge from their experience of working with other children.

Parents interviewed spoke of the need for a list, a helpline or other information source that could be sent out to them at key points in the child's life, for example, at times of transition. Others recommended the use of an electronic register via their GP or paediatrician that would flag up when they needed additional support or information. Parents of young people with autism recounted that information about autism had improved significantly over time since their son or daughter was first diagnosed; however, this was not evident in the accounts of parents whose children had other impairments.

\section{Getting the balance right: parent or professional as expert?}

As the years went by, and parents developed expertise about their child's needs and what they could expect from services, their confidence in decision making grew. Some parents said that professionals, at times, were willing to act on their wishes, even when their opinions differed. For example, a nurse was able to ensure that a 15 year old young person was admitted to a children's ward, even though the 'cut-off' was 14 . Professionals who actively listened to parents in this way were highly respected by parents. Professionals who knew the family well sometimes acknowledged and recognised parents' expertise:

I remember our GP was in here [at home] years ago and... he said [mother] you're the expert here. All I can say to you is whatever help and support we can be to you, just phone us...

[Mother of a 19 year old with physical, cognitive and communication impairment] 
On occasion, professionals positioned themselves as expert, without taking into account parents' views. This was frustrating for parents, particularly in cases where they did not have concrete evidence for their 'gut' feelings. Parents felt that whilst their knowledge was limited, they knew their child best, and at times there was evidence of a power struggle. While these were reported as isolated incidents, they created much frustration and upset and parents recalled them in great detail some years later.

Despite emphasising their own role in decision making, parents thought it was important that professionals made an effort to get to know their child. Parents were impressed when they went to meetings and professionals appeared to know their child, their likes and dislikes and their personality well. This gave parents some reassurance when decisions were being made as it implied that professionals cared about their child as an individual and them as a family.

\section{Discussion}

The aim of this article was to report parents' experiences of participating in decisions about their son or daughter's health and/or social care. Parents of disabled children continue to highlight the importance of feeling empowered and working in partnership with professionals (Hayles et al. 2015) and such an approach was evidenced in this research. The lead role of mothers in caring for and making decisions with professionals about their disabled child was evident from participants' accounts and mirrors the findings of previous studies, such as those summarised by Read (2000). The key role that mothers played in supporting their child in decision making processes has also been evidenced in other studies (Mitchell, 2012a; Mitchell, 2012b). However, findings of this research also suggest that fathers play an 
important part in providing vital support to mothers where decision making is concerned. While seldom reported in previous literature, fathers of disabled children in research by Huang and colleagues (2011) highlighted that professionals talked mostly to mothers, potentially reinforcing the passivity of fathers in interactions with them. Professionals therefore, have an important role to play in fostering the participation of fathers and actively involving them and drawing them in to decision making processes.

The finding that many parents felt the need to 'fight' for their child to ensure that their needs were met has been evidenced in numerous previous studies (see also Bennett, 2009; Slade et al. 2009; Pilnick et al. 2011; Resch et al. 2010; Care Quality Commission, 2012; Maddison and Beresford, 2012a; Brooks et al. 2013) and this was associated with a great deal of stress. By actively listening to mothers and by recognising their expertise, professionals can alleviate some of the stress they experience. Parents in this research felt that resources were limited given the recent 'cuts' and some believed that sometimes they were not told about services to prevent them asking for them. Previous studies report similar findings and highlight the importance of trust in professionals during decision making processes (Avis and Reardon, 2008; Huang et al. 2011; Maddison and Beresford, 2012a; Maddison and Beresford, 2012b; Hodgetts et al. 2013). Having said that, many parents who took part in this research reported positive relationships with professionals within the Trust and a willingness to go 'over and above' the call of duty.

Many parents in this study demonstrated a reluctance to talk to their child about their impairment or diagnosis and found it difficult to encourage their growing independence. Lohan et al. (2015) suggest that such over-protectiveness or difficulty in ' letting' go may impact on the development of the child or young person's autonomy and independence. In a study by Nguyen et al. (2016), health care providers recognised the need to foster young people's independence where their health is concerned whilst enabling and supporting parents 
to 'let' go. The relationship between developing children and young people, parents and professionals is a dynamic and complex. However, as the authors point out, professionals have a key role to play as enablers and collaborators to support both parents and young people as they develop and mature into adulthood.

An important aspect of the research was the continuing difficulty in accessing information, a feature repeatedly reported within the literature (Slade et al. 2009; Resch et al. 2010; Brooks et al. 2013; Hayles et al. 2015) . Parents of disabled children identify the provision of information about their child's condition and the provision of services as one of their core needs (Sahay et al. 2013). Some parents in this research found out important information by 'accident', a finding reported in other studies (Redmond and Richardson, 2003; Maddison and Beresford, 2012a; Hayles et al. 2015). It is encouraging, however, that parents of autistic children in this research reported a marked increase in the availability of information about autism and available services over time. The Autism Act (Northern Ireland) (2011) and Autism Review (Maginnis, 2008) in Northern Ireland may have contributed to this finding. However, this was not apparent for those with other impairments. In Northern Ireland, a number of initiatives have been introduced since the time of data collection to try and address this issue. Firstly, the development of local 'Family Support Hubs'. These hubs (see www.cypsp.org/family-support-hubs/\#ffs-tabbed-163) signpost families to appropriate local services and provide early intervention services. Secondly, 'Family Support NI (see www.familysupportni.gov.uk) is since available, a website dedicated to providing online information for families. However, as indicated in both the survey and parent interviews, the internet was not widely used by parents in this research. Parents in this research wanted reliable, face to face or written information but will use the internet to find information that is not available from other resources. Nonetheless, the relatively low frequency of internet use in the survey in this research is surprising. Parents of disabled children may experience 
financial hardship (Contact a Family, 2016) and this may also have affected access to the internet for some parents.

Not all parents want information at any given time. Several parents in this research were not ready to seek or hear information in the early stages following the diagnosis of their child (see also Keene Reder and Serwint, 2009). Hyde et al. (2010) point out that decision making often has a strong affective component and the provision of information (particularly in the early stages or during periods of transition) can be underpinned by parents' emotional trauma (see also Narramore, 2008;Eckersley, 2009; Resch et al. 2010). Thus, professionals need to be aware of the individual needs of the family. Indeed several parents recounted instances where professionals were sensitive to their needs at this time.

The survey showed that, for around two thirds of parents, information came almost equally from professionals and parents, emphasising the strength of peer support for parents of disabled children. It also highlights the potential importance of local parent advocacy groups, both as mechanisms for support and sources of information, as well as their core role in facilitating service user participation. Previous authors (Goodley and Tregaskis, 2006; Jackson, 2008; Shilling et al. 2014) also report the importance parents place on talking to other parents in the same situation as themselves in order to share experiences and knowledge.

The importance of positioning parents as experts is enshrined in family centred and partnership approaches to care (Smith and Coleman, 2009). Evidence for the effectiveness of partnership working with families of disabled children is starting to emerge (Kuhlthau et al. 2011). This research provides evidence that working in partnership with parents of disabled children and recognition of their expertise by professionals is highly desired and valued by parents. 


\section{Limitations of the research}

There were several limitations to this research. The number of participants was relatively small; however, generalisability to the population as a whole was not the aim of this research. The response rate from the parent survey $(24 \%)$ was less than hoped for, and caution is required when interpreting the findings. Nevertheless, the survey did provide important information and informed the more in depth, qualitative aspect of the research.

This research raises some important issues that warrant further enquiry. Thirteen percent of families had more than one disabled child and there was not sufficient data to draw comparisons between these families and those with one disabled child, an issue that would need addressed in future research. There is an emerging literature about the experiences of fathers of disabled children (see for example, Huang et al. 2011). This research has highlighted the need for further work in this area, specifically around their perceived and desired role in decision making. The challenges that parents face in talking to their disabled child about their impairment is also an under researched area that requires further enquiry.

\section{Recommendations for policy, practice and services}

1. The findings of this research, as indicated in the parent interviews, demonstrated that professionals' core skills and qualities, for example, caring attitudes, the ability to listen, trustworthiness and reliability and a good knowledge base can go a long way in buffering the experiences of parents and promoting their participation. Feedback from service users should be used to monitor and engender these core skills in professionals and utilised during appraisal and supervision processes. 
2. Professionals need to recognise the important supportive role fathers play in decision making processes, and in so doing, fathers may wish to become more involved. In particular, professionals need to direct their communications to both parents as, regardless of who makes the decisions, both are important.

3. The findings of this research, both from the survey data and parent interviews, suggest that the mechanisms of information provision were not always effective for parents and this needs further attention. The launch of Family Support Hubs and web-based information about services in Northern Ireland is positive. However, many parents in this research did not use web-based information. Written resources are, therefore, still required for those who are not familiar with electronic methods or cannot afford internet access. Recommendations by Mitchell and Sloper $(2000 ; 2002)$ around user friendly information for families with disabled children may inform such resources.

4. A 'flag' system at times of transitions to nursery, primary, secondary or special school, leaving school and moving to adult services would provide a useful mechanism, alerting professionals when families are approaching such times in order to provide information and support at these key times in the child's life. It was apparent from the parent interviews that at these times of transition, important decisions were made. Parents need access to updated information about options within their locality and professionals need to engage in early collaborative transition planning.

5. Parents, at times, find it difficult to talk to their disabled child and provide them with information about their impairment. Specific parenting programmes, associated guidance and advice may help parents to find positive ways of engaging in such discussions and encourage their child's autonomy as they gradually 'let go'.

6. The voluntary sector plays a vital role in the provision of information (see Table 1). Continued funding of local service user groups and the voluntary sector is vital to sustaining, improving and providing quality services for families. 


\section{Conclusion}

The participation of service users in health and social care decisions remains high on the policy agenda within Northern Ireland and across the UK. This study highlights the importance that parents of disabled children and young people attach to their involvement in decision making. The basic skills and qualities of professionals remain key to the provision of partnership and family centred ways of working. However, there is more work to be done. Professionals working with parents of disabled children and young people need to ensure that they engage parents in decision making appropriately, continue to develop their knowledge and skills, liaise with colleagues from other disciplines and agencies and update themselves about what is available for families within their locality and further afield. The provision of information requires further attention and investment to ensure that parents are enabled to make informed decisions about their child's care. Achieving this will ensure that parents are adequately supported and every disabled child reaches their own potential.

\section{Key points}

- The participation of service users in decisions that affect them is a public policy priority and an essential aspect of best practice in health and social care.

- Parents, particularly mothers, take a lead role in decision making about their child.

- Professionals who listen and recognise parents as experts are highly respected and valued by parents.

- More research and guidance is needed about talking to children about disability.

- The provision of information for remains problematic for families and requires urgent attention.

\section{References}

Avis, M. and Reardon, R. (2008) Understanding the views of parents of children with special needs about the nursing care their child receives when in hospital: a qualitative research. Journal of Child Health Care, 12,1,7-17. 
Bennett, E. (2009) What makes my family stronger: A report into what makes families with disabled children stronger - socially, emotionally and practically. Available from www.cafamily.org.uk Accessed 22/7/09.

Brooks, F., Bloomfield, L., Offredy, M. and Shaughnessy, P. (2013) Evaluation of services for children with complex needs: mapping service provision in one NHS Trust. Primary Health Care Research and Development,14,1,52-62.

Care Quality Commission (2012) Health care for disabled children and young people: A review of how the health care needs of disabled children and young people are met by the commissioners and providers health care in England. UK: Care Quality Commission.

Contact a Family (2014) Counting the costs. Available at:

http://www.cafamily.org.uk/media/805120/counting_the_costs_2014_uk_report.pdf 2014. Accessed 17/8/16.

Dahlberg, K., Dahlberg, H. and Nystrom, M. (2008) Reflective Lifeworld Research. Hungary: Studentlitteratur.

Duffy, J. (2008) Looking out from the middle: User involvement in health and social care in Northern Ireland. London: SCIE. Available from www.scie.org.uk Accessed 17/8/16.

Eckersley, J. (2009) Coping when your child has cerebral palsy. London: Sheldon Press.

Egilson, S., T. (2011) Parent perspectives of therapy services for their children with physical disabilities. Scandanavian Journal of Caring Sciences, 25,277-284.

Franklin, A. and Sloper, P. (2009) Supporting the participation of disabled children and young people in decision-making. Children and Society, 23,3-15.

Goodley, D. and Tregaskis, C. (2006) Storying disability and impairment: Retrospective accounts of disabled family life. Qualitative Health Research, 16,5,630-646.

Hayles, E., Harvey, D., Plummer, D. and Jones, A. (2015) Parents' experiences of health care for their children with cerebral palsy. Qualitative Health Research, 25,8,1139-1154.

Hodgetts, S., Nicholas, D., Zwaigenbaum, L. and McConnell, D. (2013) Parents' and professionals perceptions of family centred care for children with autism spectrum disorder across service sectors. Social Science \& Medicine, 96,138-146.

Huang, Y., Tsai, S. and Kellett, U. (2011) Fathers of children with disabilities: encounters with health professionals in a Chinese context. Journal of Clinical Nursing, 21, 198-206.

Hyde, M., Punch, R. and Komesaroff, L. (2010) Coming to a decision about cochlear implantation: parents making choices for their deaf children. Journal of deaf studies and deaf education, 15,2,162-78.

Jackson, C. (2008) A systematic review of decision support needs of parents making child health decisions. Health Expectations, 11,232-251.

Keene Reder, E.A. and Serwint, J.R. (2009) Until the last breath. Exploring the concept of hope for parents and health professionals during a child's serious illness. Archives of Pediatric Adolescent Medicine, 163,7,653-657. 
Kuhlthau, K.A., Bloom, S., Van Cleave, J., Knapp, A.A.A., Romm, D., Klatka, K., Homer, C.J., Newacheck, P.W. and Perrin, J.M. (2011) Evidence for family centred care for children with special health care needs: A systematic review. Academic Pediatrics, 11,2,136-43.

\section{Lohan, A., Morawska, A., Mitchell., A. (2015) A systematic review of parenting} interventions for parents of children with type 1 diabetes. Child: Care, Health and Development. 41,6, 803-817.

Lundeby, H. and Tossebro, J. (2008) Exploring the experiences of 'Not being listened to' from the perspective of parents with disabled children. Scandanavian Journal of Disability Research,10,4,258-274.

Maddison, J. and Beresford, B. (2012a) Decision-making around moving on from full time education: the roles and experiences of parents of disabled young people with degenerative conditions. Health and Social Care in the Community,20,5,477-487.

Maddison, J and Beresford, B. (2012b) The development of satisfaction with service-related choices for disabled young people with degenerative conditions: evidence from parents' accounts. Health and Social Care in the Community, 20,4,388-399.

Maginnis, K. (2008) Independent review of autism services. Available at:

http://www.thehealthwell.info/node/800042?\&content=resource\&member $=799178 \&$ catalogu $\mathrm{e}=$ Research\%20and\%20Evaluation,Report\&collection=Mental\%20Health\%20\&tokens_com plete $=$ true http://www.dhsspsni.gov.uk/independent_review_of_autism_services_final_report.pdf . Accessed 14/4/13.

Mitchell, W. and Sloper, P. (2000) User-friendly information for families with disabled children. A guide to good practice.UK: York Publishing Services Ltd.

Mitchell, W. and Sloper, P. (2002) Information that informs rather than alienates families with disabled children: Developing a model of good practice. Health and Social Care in the Community, 10,2,74-81.

Mitchell, W. A. (2012a) Making choices about medical interventions: the experience of disabled young people with degenerative conditions. Health Expectations doi:10.1111.j13697625.2011.00752.x

Mitchell, W. A. (2012b) Perspectives of disabled young people with degenerative conditions on making choices with parents and peers. Qualitative Social Work; 11,621.

McNeilly, P., Macdonald, G. and Kelly, B. (2015) The participation of disabled children and young people: A social justice perspective. Child Care in Practice, 21,3,266-286.

Narramore, N. (2008) Meeting the emotional needs of parents who have a child with complex needs. Journal of Children and Young People's Nursing, 2,3,103-107.

Nguyen, T., Henderson, D., Stewart, D., Hlyva, O., Punthakee, Z. and Gorter, J.W. (2016) you never transition alone! Exploring the experiences of youth with chronic health conditions, parents and healthcare providers on self-management. Child: Care, Health and Development. 42,4,464-472. 
Pilnick, A., Clegg, J., Murphy, E. and Almack, K. (2011) 'Just being selfish for my own sake...': balancing the views of young adults with intellectual disabilities and their carers in transition planning. The Sociological Review, 59,2,303-323.

Read, J. (2000) Disability, the family and society: Listening to mothers. USA: OUP.

Redmond, B. and Richardson, V. (2003) Just getting on with it: Exploring the service needs of Mothers who care for young children with severe/profound and life-threatening intellectual disability. Journal of Applied Research in Intellectual Disabilities, 16,205-218.

Resch, J.A., Mireles, G., Benz, M.R., Grenwelge, C., Peterson, R. and Zhang, D. (2010) Giving parents a voice: A qualitative research of the challenges experienced by parents of children with disabilities. Rehabilitation Psychology, 55,2,139-150.

Sahay, A., Prakash, J., Khaique, A. and Kumar, P. (2013) Parents of intellectually disabled children: A research of their needs and expectations. International Journal of Humanities and Social Science Invention, 2,7,1-8.

Shilling, V., Bailey, S., Logan, S. and Morris, C. (2014) Peer support for parents of disabled children part 1: perceived outcomes of the one-to-one service: a qualitative study. Child: Care, Health and Development. 41,4,524-536.

Slade, Z., Coulter, A. and Joyce, L. (2009) Parental experience of services for disabled children: qualitative research. BMRB research. London: Department for Children, Schools and families.

Smith, J. (2013) Parents' experiences of living with a child with a long term condition: a rapid structured review of the literature. Health Expectations, 18, 452-474.

Smith, L. and Coleman, V. (2009) Child and family centred healthcare: concept, theory and practice. UK: Palgrave Macmillan.

Streubert, H.J. and Carpenter, D.T. (2011) Qualitative research in nursing. Advancing the humanistic imperative. London: Lippincott, Williams and Wilkins.

Wodehouse, G. and McGill, P. (2009) Support for family carers of children and young people with developmental disabilities and challenging behaviour: what stops it being helpful? Journal of Intellectual Disability Research, 53,7, 644-653.

Wood, D.L., McCaskill, Q.E., Winterbauer, N., Jobli, E., Wludyka, P., Stowers, K. and Livinggood, W. (2009) A multi-method assessment of satisfaction with services in the medical home by parents of children and youth with special health care needs. Maternal and Child Health, 13,5-17. 
Table 1: Sources of information to support decision making (\% parents).

\begin{tabular}{lcc}
\hline Sources of information for parents & $\begin{array}{l}\text { Health care } \\
\text { decisions }\end{array}$ & $\begin{array}{l}\text { Social care } \\
\text { decisions }\end{array}$ \\
\hline Other parents & 68 & 68 \\
Professionals & 68 & 60 \\
Voluntary organisations & 32 & 33 \\
The internet & 35 & 18 \\
\hline
\end{tabular}

